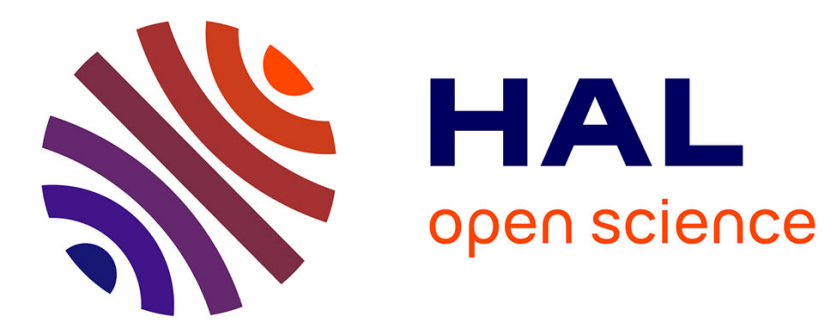

\title{
Knowledge framework for intelligent manufacturing systems
}

Ricardo Goncalves, João Sarraipa, Carlos Agostinho, Hervé Panetto

\section{To cite this version:}

Ricardo Goncalves, João Sarraipa, Carlos Agostinho, Hervé Panetto. Knowledge framework for intelligent manufacturing systems. Journal of Intelligent Manufacturing, 2011, 22 (5), pp.725-735. $10.1007 / \mathrm{s} 10845-009-0332-4$. hal-00426351

\section{HAL Id: hal-00426351 https://hal.science/hal-00426351}

Submitted on 24 Oct 2009

HAL is a multi-disciplinary open access archive for the deposit and dissemination of scientific research documents, whether they are published or not. The documents may come from teaching and research institutions in France or abroad, or from public or private research centers.
L'archive ouverte pluridisciplinaire HAL, est destinée au dépôt et à la diffusion de documents scientifiques de niveau recherche, publiés ou non, émanant des établissements d'enseignement et de recherche français ou étrangers, des laboratoires publics ou privés. 


\title{
Knowledge Framework for Intelligent Manufacturing Systems
}

\author{
Ricardo Jardim-Goncalves* João Sarraipa** Carlos Agostinho** Hervé Panetto*** \\ *DEE/FCT, Universidade Nova de Lisboa, Caparica, PORTUGAL (e-mail: rg@uninova.pt) \\ ** UNINOVA-GRIS, Group for the Research in Interoperability of Systems - Instituto de Desenvolvimento de Novas \\ Tecnologias, Caparica, Portugal (Tel: +351 211948365; e-mail: jfss@ uninova.pt; ca@ uninova.pt) \\ ***CRAN, Nancy-University, CNRS, FRANCE (e-mail: Herve.Panetto@cran.uhp-nancy.fr)
}

\begin{abstract}
Nowadays, competition is experienced not only among companies but among global supply chains and business networks. There is a demand for intelligent world-class solutions capable of reinforcing partnerships and collaborations with an improved cross-cultural understanding. However due to the proliferation of terminology, organizations from similar business environments have trouble cooperating, and are experiencing difficulties exchanging electronically vital information, such as product and manufacturing data, even when using international standards. To address similar interoperability problems, the Intelligent Manufacturing Systems program (http://www.ims.org/content/glossary) is providing an opportunity to develop industry-led R\&D initiatives, building common semantics and integrated solutions. The SMART-fm project was one of those initiatives. It led to the development of the international standard for product data representation and exchange in the furniture sector (ISO 10303-236) and identified the challenge of semantic interoperability which is today a major challenge in modern enterprise integration. This paper presents a knowledge framework to address that challenge and make interoperable intelligent manufacturing systems a reality. It proposes to use semantically enriched international product data standards, and knowledge representation elements as a basis for achieving seamless enterprise interoperability.
\end{abstract}

Keywords: Interoperability, Standards, Knowledge Representation, Intelligent Manufacturing Systems.

\section{INTRODUCTION}

The global market is willing to improve competitiveness through collaborative work and partnerships, motivating the companies to look for enhanced interoperability between computer systems and applications. Indeed, one of the difficulties enterprises are facing is the lack of interoperability of systems and software applications to manage and progress in their business. (Jardim-Gonçalves et al. 2006b) (Panetto et al., 2006).

The exchange of information and documents between partners often cannot be executed automatically or in electronic format as desirable, thus causing inefficiencies and cost increase (Brunnermeier and Martin, 1999). This is primarily due to incompatibility problems among the several information representation structures used by the different software applications along supply chains and business networks (Ray and Jones, 2006)(Panetto and Molina, 2008).

With this diffuse range of systems, industry has had its development of trading partnerships restrained, e.g., inhibiting the shared fabrication of products, software solutions. These barriers are real factors that prevent innovation and development. Therefore, standardization rapidly became an evident priority, and several dedicated reference models covering many industrial areas and related application activities, from design phase to production and commercialization, have been developed enabling industrial sectors to exchange information based on common models (Jardim-Goncalves et al., 2006a).

Together with standards development, interoperability solutions have enabled a smooth progress of manufacturing systems to a next phase, where flexibility, intelligence and reconfiguration should be reached. The 'intelligence' concept becomes more relevant because of the need to maintain effective and efficient manufacturing operations with minimum downtime under conditions of uncertainty. (A. Molina, et Al., 2005) Intelligent is taken to mean advanced and efficient manufacturing technologies, management and procedures (IMS Glossary, 2009). Therefore, one way to reach such Intelligence is exploring the use of formal ontologies as a way of specifying content-specific agreements for the sharing and reuse of knowledge among software entities (Gruber, 1995).

Competition is nowadays experienced not only among companies but among global supply chains and business networks, thus regional solutions are no longer recommended. Instead, the development of common international standards and methods helps to master the global value chain. Through international collaboration, the Intelligent Manufacturing Systems program (IMS, www.ims.org) provides an opportunity for value-chain participants to develop world-class solutions (IMS, 2005). Thus, intelligence in manufacturing systems is worldwide addressed through the IMS industry-led R\&D initiatives. 
Surveys among participants in IMS projects show that such international collaboration proves beneficial beyond the mere R\&D activity as it includes knowledge exchanges on business and market developments as well as extended business collaborations and better cross-cultural understanding (Zobel and Filos, 2006). The SMART-fm (SMART-fm, 2002) project was one of those projects that conducted to R\&D initiatives pushing forward manufacturing intelligent systems able to solve enterprise interoperability problems (Jardim-Goncalves et al, 2007c).

SMART-fm objective was defined to improve effectiveness across the entire furniture manufacturing sector by adoption of a reference method of classification and intelligent information sharing. (SMART-fm, 2006)

A major achievement of the project was to reach the enquiry stage for a standard submission, which was approved by anonymous consensus on that time. Such standard main objective is for furniture catalogue and interior design representation and exchange. It was formally defined as Application Protocol 236, i.e. AP236 (ISO, 2006). This standard is engaged in STEP, commonly known as the Standard for the Exchange of Product Model Data, which is one of the most important sets of standards for representation of product information in industrial environments (ISO/TC184-SC4, 2008), that encompasses standards for several industrial sectors as the automotive, aircraft, shipbuilding, furniture, construction, etc.

To support AP236 ISO submission, SMART-fm prepared a software suite, which included conformance testers, AP236 compliant databases, an on-line multi-lingual furniture dictionary, taxonomies, etc. Some web-services have been developed to help the integration of software tools by the internet, as for: queries for the dictionary, cataloguing browser, classification of terms, and conformance tester of files exchanged (SMART-fm, 2006). The project SMART-fm was proposed by the funStep Interest Group, a group focused in helping furniture business stakeholders in solving software issues related to its business information exchange and promoting its solutions.

The funStep Interest Group targets the enterprise interoperability among software solutions whatever the place they are used within the company and/or in different companies (funStep, 2008), with the following main objectives:

- Spread the knowledge and promote the use of product data standards within the furniture industry;

- Manage the evolution of the funStep standard;

- Co-ordinate working groups;

- Influence on the software implementations;

- Promote the adoption of results by standardization bodies.

\section{SEMANTIC INTEROPERABILITY REQUIREMENTS}

The use of AP236 or any other STEP Application Protocol alone does not solve today the enterprise interoperability problems. Indeed, typically each stakeholder has its own nomenclature and associated meaning for its business products. Therefore, the information exchanged, in spite of sharing the same structure, still may not be understood by all business partners.

Having great influence in the supply chain, namely in sectors characterized by large enterprises (which is not the case of furniture), manufacturers could force their own terminology. However that would cause chaos for their partners as they would have to deal with as many terminologies as the manufacturers they work with. Besides, this would reduce the advantages of using standards (Ray and Jones, 2006). Also, more and more the global market is costumer driven, which means that retailers and marketplaces tend to adopt a terminology that costumers are familiar with, and in turn use it down the supply chain to satisfy customization requests.

Therefore, also the manufacturing organizations must be worried with their integration with the rest of the supply chain, and the manufacturing processes are dependent on the costumer procurement.

This interoperability need is related to the semantics of the contents exchanged, and the authors, under the funStep initiative, are proposing the semantic enrichment of the furniture product data as a solution (Sarraipa, et al, 2009). The main objective is to organize the knowledge associated to the furniture products in order to enable a full understandable business messages and catalogue exchange.

This paper takes the furniture industry example to propose a framework for semantic enrichment of standard-based electronic catalogue data. The framework is built upon different Knowledge Representation Elements (KREs), namely a dictionary, a thesaurus, a reference ontology in the furniture domain and the AP236 standard itself. Together, these KREs establish the syntax and the lexicon to be used in the furniture domain. Each concept has its own definition translated to different languages, and some of the concepts are classified as the reference ones to be used by the community in their information exchange. Specific links between all the KREs enable the establishment of ontology mapping solutions, so that enterprises can keep internally their own terminologies and classification systems, and still be interoperable with their business partners.

The ISO 16100-1 (2002) standard defines manufacturing software interoperability as the 'ability to share and exchange information using common syntax and semantics to meet an application-specific functional relationship through the use of a common interface'. In alignment with this statement, the funStep initiative group intends to facilitate interoperability in the exchange of furniture catalogues and information between stakeholders. The furniture supply chain is characterized mainly by five stakeholders: suppliers, manufacturers, retailers, e-marketplaces and interior designer/architects, whose characteristics and relationships lead to different communications implementation requirements. According to Sendall et al. (2001) the analysis of a use case is one way to verify the system's functional requirements. Thus, in order to allow a common 
understanding among developers, system users, and domain experts, the authors are considering an International Product Business (IPB) use case, aiming to represent situations which could facilitate the description of how the knowledge is handled in an international plan of the furniture business. This leads research to complex situations related to semantics interoperability, and multilinguism or regional standards.

\subsection{The International Product Business (IPB) Use Case}

In IPB, the globalisation phenomena and the international product business situation drove the authors to the "leather couch" scenario analysis. This scenario is related to a "leather couch" request for quotation where a customer chooses, in a furniture catalogue, a foreign product.

The customer starts by asking the retailer for a "leather couch". The retailer shows the customer a set of catalogues with various types of "sofas". The customer looks at the catalogue and chooses the model "XPTO". However, in the catalogue it is not described if such model is available in "leather". Thus, the retailer has to ask manufacturer of the chosen model if it can be made in "leather". Since the model's manufacturer is in French, the request has to be translated. The retailer sends a fax with a request for quotation of a "XPTO en cuir" (translation of "in leather" to French). The retailer asks the customer for his contacts (e.g. email; phone; etc.) in order to be in touch.

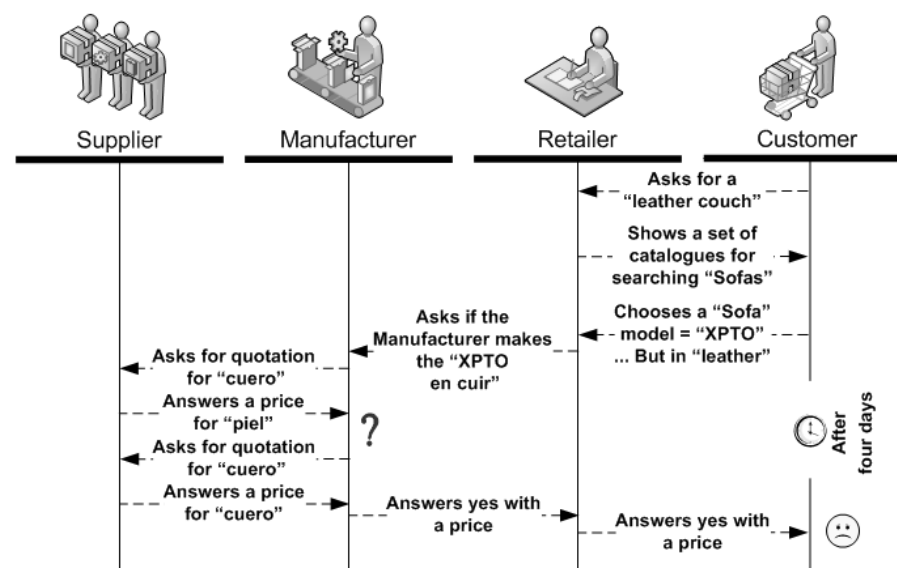

Fig. 1. Furniture Case Study Scenario

The manufacturer does not have "leather" in stock, he has to contact his supplier. Since his "leather" supplier is Spanish, he translated the request to "cuero" (translation of "leather" to Spanish). The supplier answered his request. Nevertheless, the manufacturer did not believe in the answer because the product description said "piel" (Spanish synonym word for "cuero") instead of "cuero". When the Spanish supplier received the reply asking for confirmation, he laughs because of the supposed misunderstanding that the French thought was happening. In order to avoid further interaction problems, the Spanish answered again using the "right" word - "cuero". Once the manufacturer received the quotation, he replied with the quotation for producing a "leather XPTO" sofa. After four days the customer received the answer.
The funStep initiative, under the SMART-fm project, already defined a standard, namely AP236, for the exchange of data that could be used in this use case scenario communications. Nevertheless despite the information exchange with AP236, semantic interoperability could still be improved. From a first analysis to the presented use case scenario, it was emphasized the following set of statements that describe the necessity of having a structured furniture knowledge organization:

1) The retailer knows that "couch" is equivalent to "sofa", and the catalogues containing these products mostly designate them as "sofas". Thus, the reference word is "sofa" instead of "couch".

2) The retailer only shows to the customer the catalogues that have sofa models. This implies a catalogue selection based in a classification item - "sofas".

3) Once the customer wants the model "XPTO" in "leather", the retailer had to translate this request to the language of the chosen model's manufacturer.

4) In the interaction between the manufacturer and the supplier, it was identified the need of having defined reference terms and concepts for each translated language.

5) Since the retailer is English and the manufacturer is French, the quotation was converted to the right currency.

For each of the statements described it was defined a set of requirements that was taken in consideration in the process of reaching the desirable semantics interoperability in the furniture business interactions. Such requirements were:

1) To have a domain dictionary for getting help on choosing synonyms;

2) Establishment of a set of reference terms in the domain to be used in the business communications;

3) Define an ontology for products classification in order to enable knowledge reasoning;

4) To have a multilinguism dictionary to be used in translations;

5) Define for each language a set of reference domain terms for business interactions;

6) A way to enable data transformations, as for instance in currency conversions;

As conclusion it was defined the need of having a structured furniture knowledge organization able to match these requirements in the AP236 semantic enrichment process, which will facilitate the full information interoperability establishment in the furniture business.

\section{FUNSTEP KNOWLEDGE ARCHITECTURE}

Data can exist in multiple ways, independently of being usable or not. In the raw format, it does not have meaning in and of itself. However, information is data that has been given meaning by way of relational connection to a context (Breiter and Light, 2004). Still, in information, this "meaning" can be useful for some, but not necessarily to all. As Bellinger et al. (2004) define, information embodies the understanding of a relationship of some sort, possibly cause and effect. Thus, people might "memorize" information (as 
less-aspiring test-bound students often do), but still be unable to understand it because it requires a true cognitive and analytical ability, i.e. knowledge.

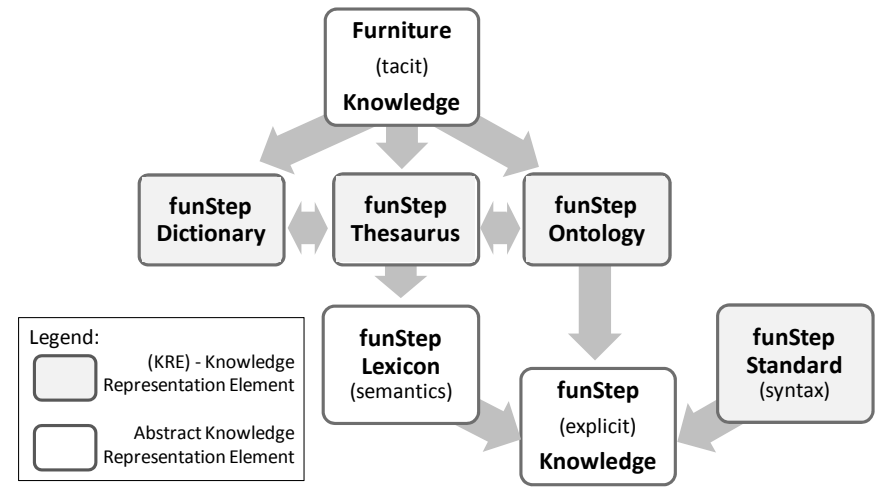

Fig. 2. funStep knowledge architecture

Nonaka et al. (2001) defines two kinds of knowledge: 1) Tacit knowledge: that people carry in their minds, which provides context for people, places, ideas, and experiences; 2) Explicit knowledge: that has been or can be articulated, codified, and stored in certain media.

funStep endeavours to gather the tacit knowledge that furniture domain stakeholders hold into machine interpretable knowledge bases. Closing this gap, funStep will obtain the (explicit) knowledge which should be stored in a structured organized way, where syntax and lexical semantics are integrated (Pustejovsky, 1993). For reaching that objective, the authors are proposing to integrate the funStep standard (AP236) with the reference funStep Lexicon, which embodies the reference concepts and semantics, and with a funStep ontology, which embraces product classification to its related properties. This leads to the knowledge architecture definition (Fig. 2). Therefore, the integrated knowledge is composed by four KREs (Fig. 3): the funStep Ontology; the funStep Thesaurus; the funStep Dictionary, and the funStep AP236 ISO Standard.

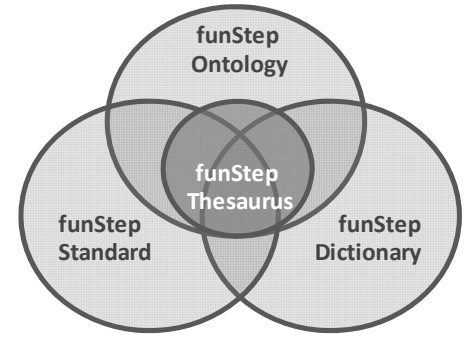

Fig. 3. funStep KREs domains intersection

For a good explicit knowledge representation, it is needed to have significant input from the tacit source (i.e., domain experts). Thus, such characteristic requires a knowledge architecture enabling the management of the evolution between the KREs. The evolution of the first three KREs leads to the funStep Lexicon establishment which is an abstract KRE in the sense that it is composed by thesaurus contents, i.e. concepts and definitions. On the other hand, the funStep explicit knowledge KRE is another abstract KRE since it is composed by the addition of the funStep Lexicon with the ontology and the standard itself. In conclusion the funStep explicit knowledge represents all the furniture machine interpretable knowledge where the funStep dictionary and the thesaurus are supporting KREs to the funStep Lexicon establishment and maintenance.

Each one of these KREs has a particular scope, role and different objectives in the overall funStep Product Knowledge Architecture, where their focus domains intersect each other partially. The funStep thesaurus domain is totally included in the funStep ontology, while the other KREs have particular information which is not shared with the others.

Going back to the scenario presented before, the term "couch" is represented in the dictionary but not in other KREs. The term "sofa" could appear in all the KREs, since it is a reference term in the business. The specific "XPTO" term that represents a sofa model could appear in the ontology and in the standard, since it is a product classified as sofa and it is a term that could be mentioned in the standard for product catalogue exchange.

\subsection{The funStep Dictionary}

A domain dictionary has been found to be one of the most useful tools for a domain analysis. The dictionary lessens a great deal of miscommunication by providing users with information: 1) in a central location to look for terms and abbreviations that are completely new; 2) where definitions of terms are used differently or in a very specific way within the domain (CMU, 2007).
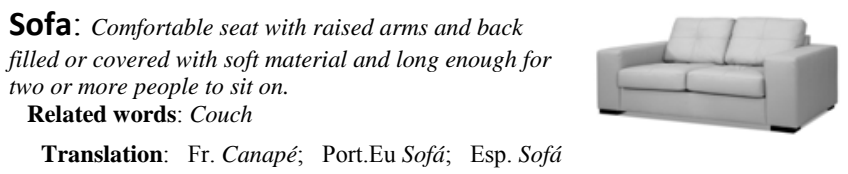

\section{Fig. 4. The funStep Dictionary}

The funStep dictionary supports a multilingual collection of terms, thus enabling an enriched coordination between international partners. Also, the terms are associated to a description, synonyms, other related terms, and optionally multimedia items, such as images, sounds or videos. Continuing with the "leather couch" scenario, Fig. 4 represents a view of the dictionary with the meaning of the term "Sofa"; its picture; its related words - in this case it is "couch"; and some translations (e.g. "canapé" in French; "Sofá" in Spanish and Portuguese).

\subsection{The funStep Ontology}

An ontology is an explicit specification of a conceptualization (Gruber, 1993). Thus, ontologies could provide a basis for expressing and structuring the knowledge of an organisation.

In the context of the funStep initiative, its main objective is to represent all the knowledge associated to furniture products, enabling semi-automatic classification. The funStep ontology 
started to be developed by the funStep initiative during the COFURN European Project (COFURN, 2002), based on search criteria and codes which were used than for furniture products classification in electronic commerce. Afterwards, during the SMART-fm project, it was upgraded through a harmonization process from existing taxonomies of different fields such as e-marketplaces and e-commerce websites (Jardim-Goncalves, et.al, 2007b).

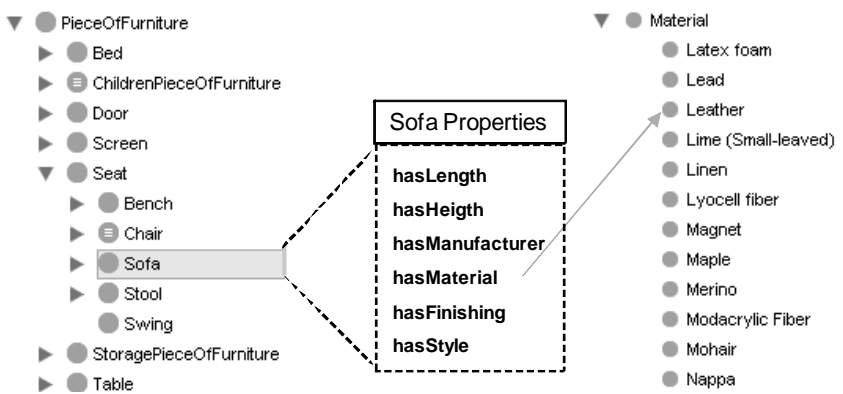

Fig. 5 Subset of the funStep Ontology taxonomy

Nowadays, we are using semantic comparisons, basic lexicon establishment, harmonization among other ontologies and other operations on knowledge base representations. Fig. 5 depicts a subset of the funStep ontology taxonomy emphasizing the furniture product characteristics mentioned in the "leather couch" scenario - classification as "leather sofa".

\subsection{The funStep Thesaurus}

The basic lexicon establishment is reached by the development of a thesaurus on the domain - the funStep Thesaurus. This is composed by a set of domain reference terms and concepts, clustered on the basis of their similarity, organized by means of semantic relationships (e.g., equivalence, subsumption, generalization, disjunction ...), thus enabling a better retrieval process of semantically related terms (Missikoff et al. 2004). A thesaurus can serve as a controlled vocabulary where terms are constrained to its domain-specific meanings, avoiding the problem of ambiguity (Gatlin, 2005). The funStep thesaurus envisages a multi-national scope of vocabulary, where terms with the same meaning coexist in multiple languages. Multilingual thesauri can be used to translate queries, by expanding the query to one or more target languages (Ballesteros and Croft, 1996). Still in the "leather couch" use case scenario, the multilingual thesaurus addresses the definition of the related words "Leather", "Cuir", and "Cuero".

The construction of a multilingual thesaurus typically begins with the analysis of business messages, costumer search requests, common domain documents and other knowledge sources (Soergel, 1997). Therefore, the thesaurus can be seen as a collection of parts of the dictionary, ontology and the standard itself (see Fig. 3).

Again, following the "leather couch" scenario, a subset of the multilingual thesaurus, can be as follows, where the last three concepts are linked each other since they represent the same meaning exactly in English, French and Spanish (Fig. 6):

Sofa: A sofa is a long upholstered seat typically with a back and arms for the comfortable seating of more than one person.

Leather: A material made from animal skins treated by a special process.

Cuir: Matériaux fait à partir de peaux animales traitées par un processus spécial.

Cuero: Un material hecho a partir de pieles de animales tratados con un proceso especial.
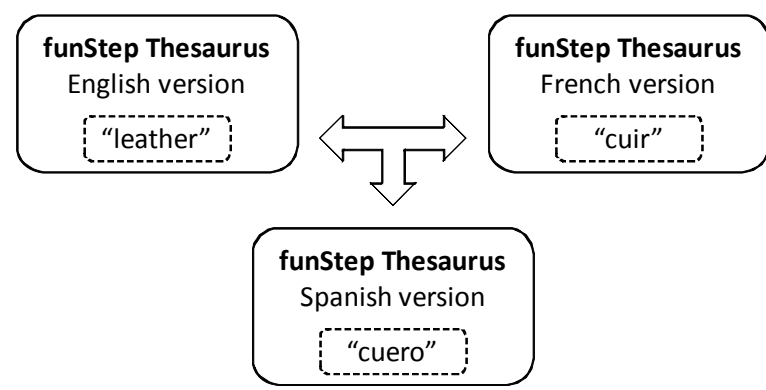

Fig. 6. funStep Thesaurus instances

\subsection{The funStep AP236 Standard}

To allow enterprise applications to interoperate seamlessly in information exchange, there is a need for a unified and standardized representation of product data (Ray and Jones, 2006; Jardim-Goncalves et al., 2007a), i.e., the funStep ISO AP236 standard (ISO, 2006). AP236 defines the reference open structure for catalogue and product data representation under industrial domains of the furniture sector, helping on the information interoperability at a syntactical level. The External Classification; and Multilinguism modules of funstep standard are examples of relevance for semantic enrichment.

\section{THE FUNSTEP KNOWLEDGE FRAMEWORK}

Semantics is the study of language units meaning and their combinations (Willerval et al., 1989). Therefore, semantic enrichment is the act or process of adding specific meaning elements to some knowledge representation structure in a domain, to help on the information clarification (Boudjlida and Panetto, 2007). The funStep standard semantic enrichment is characterized as being performed at two basic levels (Boudjlida, et al, 2007) (Sarraipa et. al, 2007): 1) Terminological annotation, by using the terms identified in the Lexicon (Thesaurus); 2) Semantic annotation, by using concepts and expressions drawn from the Ontology.

Both levels are conducted through a knowledge framework based on the KREs identified: the funStep dictionary, thesaurus, ontology and standard data. Matching the requirements identified in the use case presented, the authors' proposal for the funStep framework (Fig. 7) is built up on 
web services technology enabling interoperable open services over the internet between the funStep knowledge client systems and the funStep knowledge server (Jardim-Gonçalves et al. 2006b). This architecture is composed by three parts: 1) natural language dictionary server; 2) funStep knowledge server and 3) funStep knowledge clients.

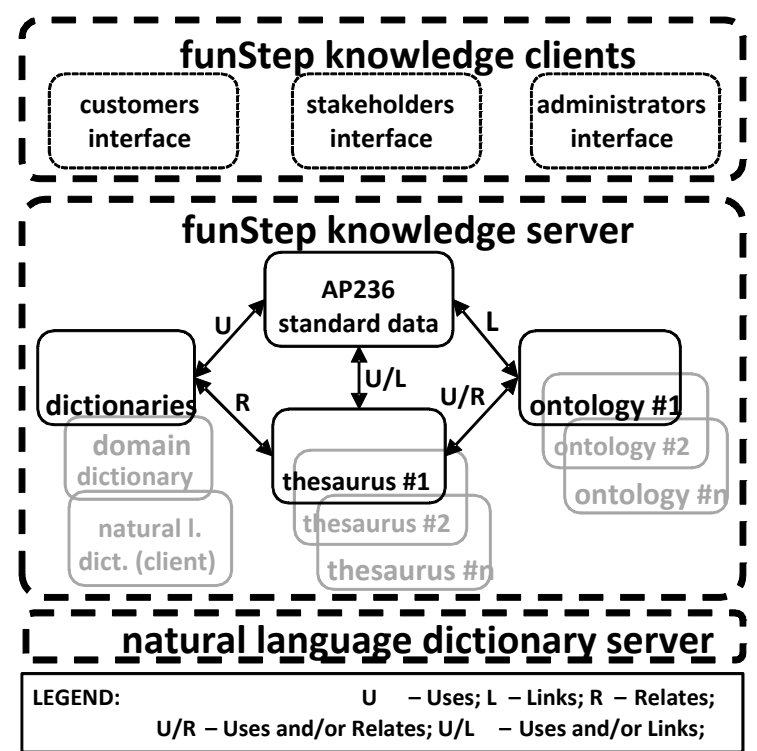

Fig. 7. funStep Knowledge Framework

\subsection{The funStep knowledge server}

The "funStep knowledge server" is composed by the four funStep KREs described in section 3, whose relationships enable the semantic enrichment of the standards data.

The AP236 standard data has links to the ontology for products classification, and to thesaurus concepts for external annotation to its data representation elements. This is made as explained before for the External Classification example. Thesaurus concepts and dictionaries terms (from domain and natural language dictionaries) are used in the knowledge server data representation and multilinguism translations. Some of the terms and meanings in the domain dictionary are related to thesaurus elements, which facilitate the retrieval of the related reference concepts, e.g. the "couch" concept was replaced by the reference concept "sofa".

The ontology is closely related to the thesaurus, sharing a very similar structure. This enables the usage of concepts definitions from both KREs for semantic clarification and to establish a relationship between them. Therefore, the funStep Ontology could be easily translated taking as source the thesaurus for the target language.

\subsection{The funStep knowledge clients}

The "funStep knowledge clients" are interfacing the framework engine with the funStep knowledge users, which can be administrators, customers, or stakeholders.
The role of funStep system administrators is mainly related to systems evolution and maintenance, i.e., KREs in this framework case.

Traditionally, in the furniture sector, customer interfaces are mainly focused on simple product search. This framework intends to go further ahead, enabling software developers with skills to develop enhanced intelligent products search engines based on knowledge reasoning.

The stakeholders' interfaces is related to provide the appropriate features to enable furniture stakeholders access to funStep knowledge in order to use it as reference and to contribute to their evolution.

\subsection{Natural Language Dictionary (NLD) server}

The NLD server complements the domain dictionary in the translation procedure of natural language information used within the AP236 standard data. For instance, the request for quotation sentence sent in the use case scenario was translated from "ХРTO in leather" to the French "ХРTO en cuir". The "leather" word was translated by the domain dictionary, but the "in" word it was translated through a NLD.

\subsection{Clouds of services}

The interoperability between the knowledge server and the knowledge clients (Fig. 7), and between the knowledge server and natural language dictionary server is established and controlled by two clouds of services, i.e., 1) a cloud of knowledge services and 2) a cloud of natural language dictionary services. These two clouds provide the required services available through the internet, that allows a global access and control of the knowledge functionalities of the funStep platform throughout its knowledge server, connecting the supporting functionalities of the natural language dictionary and, on the other side, the funStep knowledge clients themselves.

\section{SEMANTIC ENRICHMENT FOR INTELLIGENT PRODUCT CATALOGUES}

The ISO 10303-236, i.e. AP236 or funStep standard, defines a formalized structure for catalogue and product data under the industrial domain of furniture sector. The standard is originally divided in six different implementation sets: catalogue, geometry, rules and expressions, room decoration, catalogue plus geometry plus expressions, and the whole standard (ISO, 2006).

The AP236 standard helps on the information interoperability at a syntactical level. In each implementation set there are several resources that establish the way how the information components must be represented. From all of the standard resources, three are of relevance for the standard semantic enrichment purpose, i.e. A) Internal Classification; B) External Classification; and C) Multilinguism (INNOVAFUN, 2007). 


\section{A) Internal Classification}

Each company has its own product nomenclature and structure. This is easily verified not only in the way catalogues are arranged, but also in the different designations companies use for the same concept. This way, normally legacy product taxonomies and classification systems, i.e. thesaurus or ontologies in the funStep knowledge case, are shared with other enterprises when doing business, in order to create a common understanding.

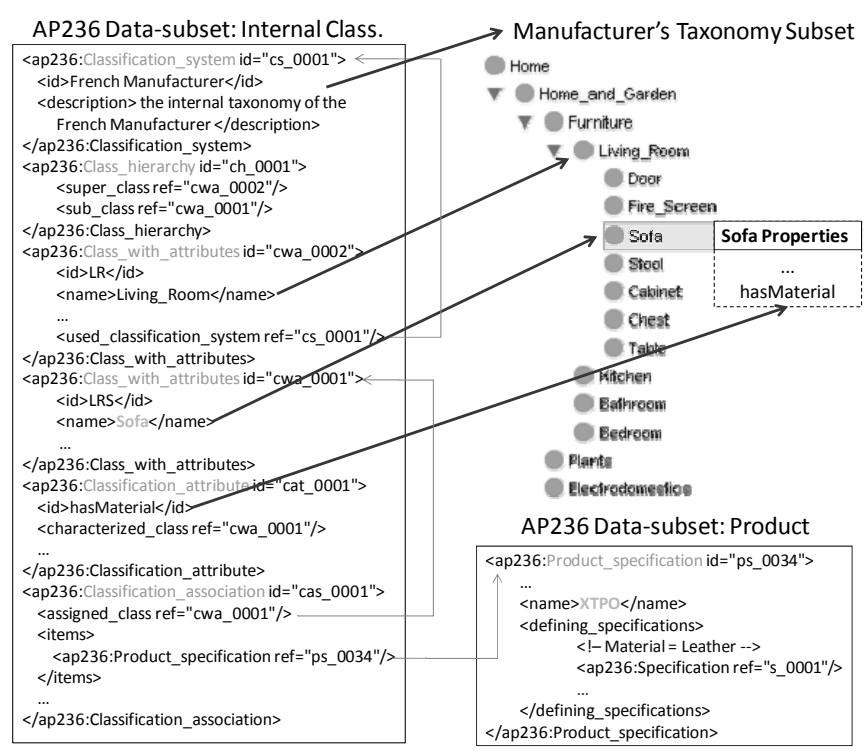

Fig. 8. AP236 Internal Classification Example

AP236 provides a mechanism to establish a direct link between the context and the classes of products present in the catalogue. The classification entities of the standard allow making one or more associations between classes of meaning and concepts, which may be helpful if one wants to make a taxonomy apart from its own just meant for the end user. With internal classification, the taxonomies are embedded in the product data file being exchanged among organizations.

Continuing with the "leather couch" scenario, if the user decides to go forward with the purchase of the "XPTO couch" in "leather", the manufacturer will have to produce it, and eventually will send the product details to the retailer, so that he can sell it in the future. At that time, the manufacturer can send the retailer its own taxonomy with the classified product. Fig. 8 illustrates how that information would look in AP236 and how it matches the taxonomy terms (normally would be French due to the manufacturer nationality, but presented in English for easy-reading purposes).

The AP236 data model enables to specify a structure of classes, attributes and their relationships using the "class_with_attributes", "class_attribute", and "classification_hierarchy" entities. As illustrated in the figure, those classes also enable to establish a direct relationship with the product in the catalogue, i.e. "product_specification", using the entity "classification_association".

B)External Classification
For an improved business, networks of organizations may define, or use shared reference ontologies or thesaurus, instead of legacy taxonomies. In this case, when exchanging product information, they should classify their products using that reference nomenclature. AP236 provides a mechanism for that, i.e. the external classification.

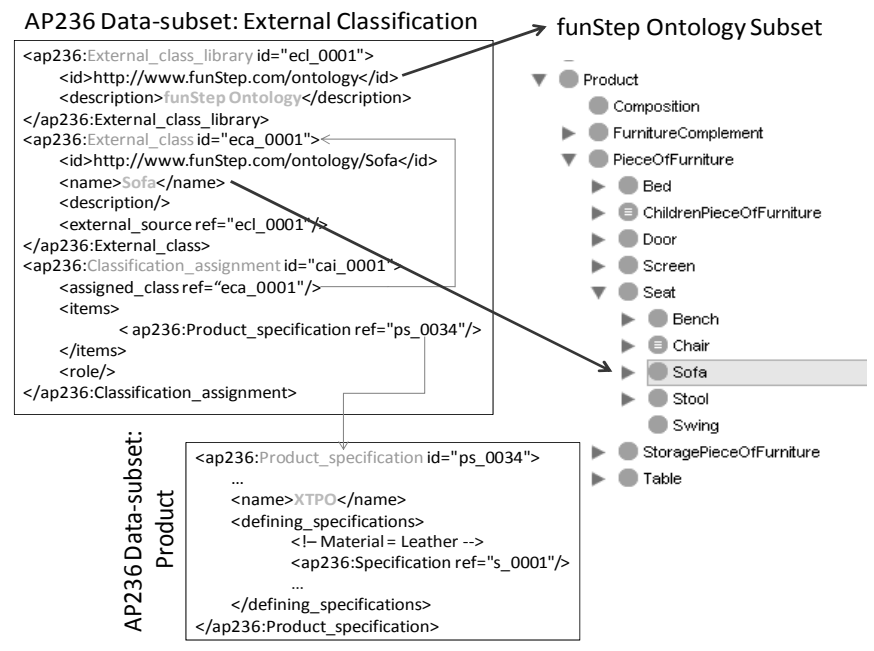

Fig. 9. AP236 External Classification Example

External classification enables a direct link between the context and the classes of products. Nevertheless, in this case, the mentioned link uses meanings that are expressed in libraries physically described in remote locations. Fig. 9 illustrates how external classification works. The manufacturer links with the funStep reference ontology, instead of sending its own, using the AP236 entities: "external_class" and "external_class_library", to identity the externally defined concepts, and "classification_assignment" to establish the link with the product in the catalogue.

To illustrate how external classification works, Fig. 9 uses the same example of internal classification, however in this case the link will be established with the funStep reference ontology. Here, the AP236 entities used are: "external_class" and "external_class_library", to identity the externally defined concepts, and "classification_assignment" to establish the link with the product in the catalogue.

\section{C) Multilinguism Issues}

For a better internationalization of the market, companies must be able to send their products and associated information in several languages, especially in the language the receiver company speaks. The multilinguism resource of AP236 addresses such need, so that any organization could receive data in their native language independently of where it was introduced or manufactured. In the "leather couch" scenario, multiliguism can be used at the time of catalogue publication or update (i.e., at manufacturer-retailer communication).

Multilinguism allows the translation of the attributes of AP236 entities in any number of languages. In Fig. 10, it is possible to notice that the AP236 entity "language" is used to 
indicate the reference language. The entity "language indication" points to the attribute that one wants to translate, and the "attribute translation assignment" specifies the translation itself. In this case, it is the value of the attribute "name" that is being translated from the French "cuir" to the English "leather".

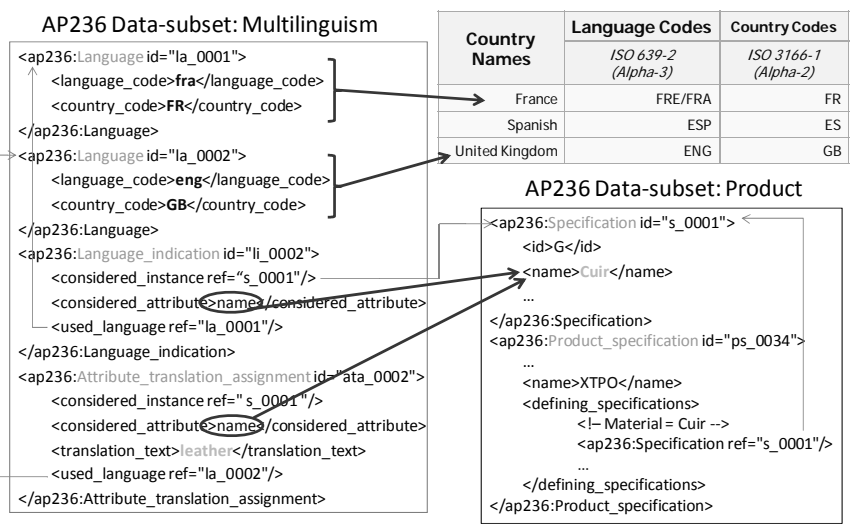

Fig. 10. AP236 Multilinguism Example

\section{MANAGEMENT OF FUNSTEP KNOWLEDGE FRAMEWORK}

It is the funStep managers' committee that maintains the knowledge representation elements. Having multilingual dictionary, thesaurus and ontology, there is a need to have such a domain expert managing each of the languages and KRE's used, that analyses the specific issues related to knowledge domain representation.

Following the "leather couch" scenario, there was a necessity of having the term "leather" translated in three languages: in English, French and Spanish. Since the word leather is a reference concept in the furniture domain there is needed to have it linked with all of reference terms in each of the languages (Fig. 6). In this way the systems will be able to translate the reference terms to other reference terms avoiding misunderstanding in the meaning of such words. To have the reference concepts mapped with others in other languages, it is used a mapping tool for thesaurus concepts mapping establishment (Fig. 11). The action of establishing such mappings is made by the managers committee.

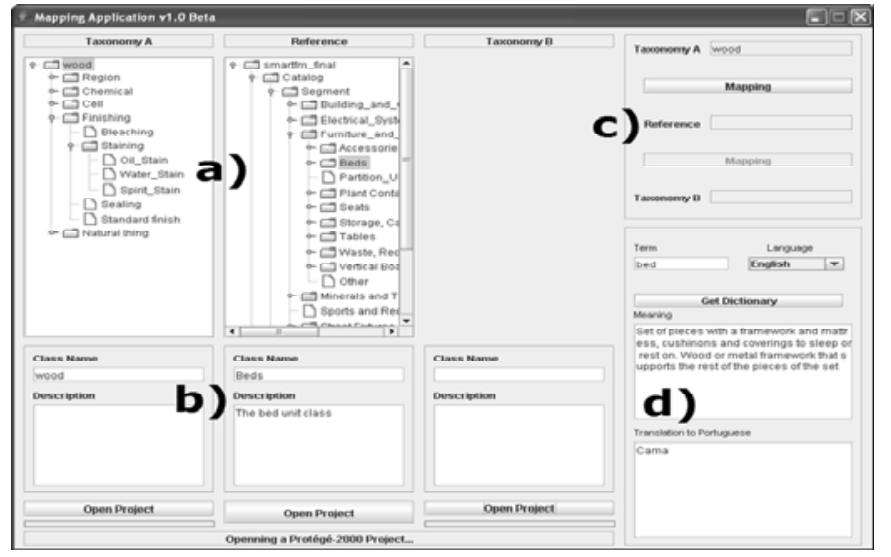

Fig. 11. Thesaurus Mapping Tool
This mapping tool is organized in four areas (Fig. 11) where in the area a) the user can select terms to map from the opened thesaurus and in the section b) appears the selected terms annotation. If the user identifies semantic similarities, then it can establish the mapping through the available functionalities in area c). In the area d) it is facilitated the access to the furniture funStep dictionary for human check and validation.

\subsection{Enterprise’s Knowledge Alignment}

Semantic mapping is an activity that attempts to relate the concepts between two organizations that share the same domain of discourse. Sarraipa et al. (2008) defined a methodology for enterprise reference ontology development, which uses a mediator ontology able to represent semantic operations: semantic mismatches; semantic transformations; mappings; and other (e.g. versioning). Such mediator ontology should be adopted for knowledge alignment, as KREs mappings facilitator.

As a mapping example from the user scenario we have been using, the request of "Leather couch" is translated to a request for a "Leather sofa". Nevertheless these mappings are related only to literal elements. However, the complexity increases when the mappings are established between property elements, which result in some complex transformations.

Back to the same example, the request of a product classified as "Leather couch" with " $n \_s e a t s=3$ ", where " $n \_s e a t s "$ is a property that indicates the number of seats in the retailer ontology, is mapped to a "Leather sofa" where the "dimension" has the "size" characterized by a "width" with a value of " 215 " and a "depth" of "90". Fig. 12 depicts an extract of the manufacturer and retailer ontologies where the referred mappings are related to.

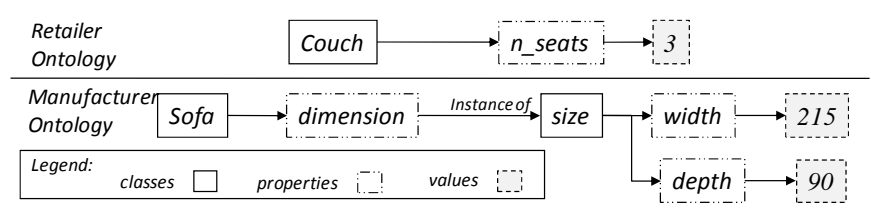

Fig. 12. Mapping example

The transformation resulted from the mapping of this example can be recorded in the mediator ontology as an axiom, which, in this specific case, is based on the following equations:

$$
\begin{aligned}
& F R(x)=n \_\operatorname{seats}(x) \\
& F E(y, z)=\operatorname{dimension}(\operatorname{size}(w i d t h(y), \operatorname{depth}(z))) \\
& F R(x)=F E(y, z) \\
& n \_s e a t s(3)=\operatorname{dimension}(\operatorname{size}(\operatorname{width}(215), \operatorname{depth}(90))) \\
& y=50+55 x \quad \Lambda \quad z=90 \\
& F R(x)=F E(y(x), z) \\
& n \_\operatorname{seats}(x)=\operatorname{dimension}(\operatorname{size}(w i d t h(50+55 x), \operatorname{depth}(90)))
\end{aligned}
$$

Equation (1) indicates a function that represents the "Leather couch" property, which, in this case, is related to more than 
one property in relationship to the manufacturer representation (2). In order to define the transformation which relates both representations, it is stated an equality between both expressions (3). After analysing empirically all the existent values that these expressions could take ((4) shows one case), it was defined two linear equations (5) which relates (1) and (2). At the end it was reached an expression that establishes a semantic relationship between both representations and that establishes the transformation equations related to each variable (6) and (7).

Thus, this mediator ontology can be used for semantic translations between enterprises exchanging data, which do not share the same semantics as a funStep knowledge organization.

\section{CONCLUSIONS}

The proposed funStep knowledge framework provides enterprise and manufacturing systems a semantically seamless communication with other stakeholders up and down the supply chain.

The development of common international standards and methods helps to master the global value chain. However, alone, product data standards do not solve today the enterprise interoperability problems. Indeed, typically each stakeholder has its own nomenclature and associated meaning for its business products. Therefore, organizations from similar business environments are having trouble cooperating.

The furniture sector is no exception, and being a manufacturing sector based mostly on small and medium enterprises is having the problem proliferated by millions of organizations. For instance, a group of enterprises which share product data information in their business activities need to have a common semantics to understand each other. Otherwise their systems might understand the data structure but not its meaning.

The authors, under the funStep initiative which is continuing the activities begun by the IMS SMART-fm project, propose the semantic enrichment of standardized product data as a solution for making interoperable intelligent manufacturing systems a reality. They endeavour to gather the tacit knowledge that furniture domain stakeholder's hold into machine interpretable knowledge bases, which should be stored in a structured organized way, where syntax and lexical semantics are integrated asexplicit knowledge.

This allows enterprises to keep their internal terminologies and classification systems, and still remain interoperable with their business partners, through the usage of knowledge mapping procedures. The funStep knowledge framework uses different KREs as catalysts to enable such semantic interoperability. Together, the domain dictionary, the thesaurus, the reference ontology and the AP236 standard itself act as explicit knowledge repository and reference lexicon for the application domain.
To complement, the domain dictionary in the translation procedure, a natural language dictionary is used. And since knowledge is evolutive and dynamic, the framework also considers its maintenance by a group of administrators, as well as the interaction with the users, e.g., customers, and stakeholders.

In the past, the funStep framework was able to deliver two levels of product data exchange interoperability compliance: (level 1) - not funStep compliant - where the messages exchanged are following any kind of format other than the AP236 standard; (level 2) - funStep compliant - where, the exchanged messages were compliant with the AP236 standard. Inside this level, there could still be different sublevels according to the parts of AP236 implemented. From the research results presented in this paper, the funStep Knowledge framework is extended adding semantics compliance to it, i.e. (level 3) - funStep knowledge compliant. With level 3 compliance, systems communications would be syntactically compliant with the AP236 standard and as well semantically compliant with the reference funStep knowledge.

In the future, the authors intend to develop further research to address the issue of interoperability maintenance, i.e. how the framework would adapt to new terminology terms, or modifications to the existing concepts. Similar problems come along with the product data level if new versions of the product data standards are released due to new market requirements. The study of complexity science is seen a possible path to understand some of those perturbations, and predict their occurrence envisaging an automatic readjustment of networked systems (Choi, et.al, 2001).

\section{REFERENCES}

Ballesteros, L. and Croft, B. (1996). Dictionary methods for cross-lingual information retrieval. In: DEXA '96 Database and Expert Systems Applications Conference, September 9-13, Zurich, Switzerland.

Bellinger, G., Castro, D., Mills, A.(2004). Data, Information, Knowledge, and Wisdom [online]. [Accessed 13 November 2008] Available from World Wide Web: http://www.systems-thinking.org/dikw/dikw.htm.

Breiter, A. and Light, D. (2004). Decision Support Systems in Schools - from Data Collection to Decision Making. In: AMCIS 2004 -Tenth Americas Conference on Information Systems, August 2004, New York, USA.

Boudjlida N., Panetto H. (2007). Enterprise Semantic Modelling for Interoperability. Proceedings of 12th IEEE Conference on Emerging Technologies and Factory Automation (ETFA'2007). 847-854, September 25-28, Patras, Greece, ISBN: 978-1-4244-0826-9

Boudjlida, N., Panetto, H., Baïna, S., Diamantini, C., Krogstie, J., Lin, Y., Sarraipa, J., Zouggar, N., Hahn, A., Delgado, M., Abian, M.-A., Nunez, M.J., (2007). INTEROP deliverable DTG4.2: Experimental Semantic Enrichment of Enterprise Models for Interoperability and its Practical Impact. EC project IST 508-011. 
Brunnermeier, S. and Martin S.A. (1999). Interoperability Cost Analysis of the U.S. Automotive Supply Chain: Final Report. DIANE Publishing.

Choi, T., Dooley, K.J., and Rungtusanatham, M. (2001). Supply networks and complex adaptive systems: control versus emergence. Journal of Operations Management, vol.19 (3), pp. $351-366$.

CMU (Carnegie Mellon University)-Domain Dictionary (2007). [Accessed 30 September 2008]. Available on: www.sei.cmu.edu/domain-engineering/domain_dict.html

COFURN. (2002). CO-operation for consensus, standardisation and interoperability to support e-com services in the FURNiture sector. EC project No. IST2000-25183.

funStep. (2008). [online]. [Accessed 12 November 2008]. Available on: http://www.funstep.org/.

Gatlin, K.A. (2005). Enhancing Cross-Language Retrieval of Comparable Corpora Through Thesaurus-Based Translation and Citation Indexing. In UNC SILS Master's Papers. School of Information and Library Science.

Gruber, T.R. (1993). A Translation Approach to Portable Ontology Specifications. Journal of Knowledge Acquisition, vol.5 (2), pp. 199-220.

Gruber, T:R: (1995). Toward Principles for the Design of Ontologies Used for Knowledge Sharing. In: International Journal Human-Computer Studies Vol. 43, Issues 5-6, Novemer 1995

IMS (2005). IMS Impact Report: History and Success of Phase I. In IMS Impact Report - IMS Inter-Regional Secretariat, Washington, D.C., January 2005.

IMS Glossary (2009). Intelligent Definition. Retrieved from the web (http://www.ims.org/content/glossary) in June 2009.

INNOVAFUN. (2007). Deliverable 1.1: Opportunities for Innovation [online]. [Accessed 12 November 2008] Available from World Wide Web: http://standards.euinnova.org/Files/Report/D1.1.Opportunities for innovati on using funStep.pdf. EC INNOVA Project No.: 031139 .

ISO. (2002). ISO 16100-1:2002. Industrial automation systems and integration - Manufacturing software capability profiling for interoperability - Part 1: Framework.

ISO. (2006). ISO 10303-236:2006. Industrial automation systems and integration - Product data representation and exchange - Part 236: Application protocol: Furniture catalog and interior design.

ISO/TC184-SC4. (2008). [online]. [Accessed 12 November 2008]. Available on: www.tc184sc4.org/SC4_Open/SC4\%20Legacy\%20Products $\% 20 \% 2$ 82001-08\%29/STEP \%2810303\%29/.

Jardim-Goncalves, R., Figay, N., Steiger, A.(2006a). Enabling interoperability of STEP Application Protocols at meta-data and knowledge level. International Journal of Technology Management, Vol. 36, N 4 / 2006 , pp. $402-421$.

Jardim-Goncalves, R., Grilo, A., Steiger, A.(2006b). Challenging the interoperability between computers in industry with MDA and SOA. Computers in Industry, Volume 57, Issues 8-9, December 2006, Pages 679-689.
Jardim-Gonçalves, R., Agostinho, C., Malo, P., and SteigerGarcao, A. (2007a). Harmonising technologies in conceptual models representation. Int. J. Product Lifecycle Management, vol.2 (2), pp. 187 - 205.

Jardim-Goncalves, R.; Silva, J. P.M.A.; Steiger-Garcao, A.; Monteiro, A. (2007b). Framework for Enhanced Interoperability through Ontological Harmonization of Enterprise Product Models in book Ontologies: A Handbook of Principles. Concepts and Applications. Integrated Series in Information Systems, Vol. 14-2007, XXIV, 915 p., 245 illus. ISBN: 978-0-387-37019-4.

Jardim-Goncalves R., Panetto H., Nuñez M.J., and SteigerGarcao A. (2007c). SMART-fm: setting interoperability in SME-based industrial environments. 51-63. In: Taisch M., Thoben K. D. and Montorio M. (eds.). Advanced Manufacturing: an ICT \& Systems Perspective, Taylor \& Francis, February 2007, ISBN 9780415429122

Missikoff M., Boudjlida N., Lenzerini M., Jeusfeld M., Johannesson P., et al. (2004). D8.1 - State of the art and state of the practice including initial possible research orientations, Interoperability Research for Networked Enterprises Applications and Software Network of Excellence, $\mathrm{n}^{\circ}$ IST 508-011, November 2004.

Molina, A., Rodriguez, C. A., Ahuett, H., Cortés, J. A., Ramírez, M., Jiménez, G. and Martinez, S.(2005). Next generation manufacturing systems: key research issues in developing and integrating reconfigurable and intelligent machines. In: International Journal of Computer Integrated Manufacturing, 18:7,525 — 536.

Nonaka, I., Konno, N., Toyama, R. (2001). Emergence of "Ba". In Nonaka, I. and Nishiguchi, T., Knowledge Emergence: Social, Technical, and Evolutionary Dimensions of Knowledge Creation, pp. 13 - 29, Oxford University Press US.

Panetto, H., Jardim-Gonçalves, R., Pereira, C. (2006). EManufacturing and Web-Based Technology for Intelligent Manufacturing and Networked Enterprise. Journal of Intelligent Manufacturing, Vol. 17 (6). pp. 639-640.

Panetto H., Molina A. (2008). Enterprise Integration and Interoperability in Manufacturing Systems: trends and issues. In: Special issue on Enterprise Integration and Interoperability in Manufacturing Systems, H. Panetto and A. Molina (Eds). Computers In Industry, 59/7, 641646, September, Elsevier, ISSN: 0166-3615

Pustejovsky, J. (1993). Semantics and the Lexicon. Springer.

Ray, S.R. and Jones, A.T. (2006). Manufacturing interoperability. Journal of Intelligent Manufacturing, vol.17 (6), pp. 681-688.

Sarraipa, J.; Zouggar, N.; Chen, D; Jardim-Goncalves, R. (2007). Annotation for Enterprise Information Management Traceability. In: Proceedings of IDETC/CIE ASME 2007.

Sarraipa, J., Silva, J., Jardim-Goncalves, R. and Monteiro, A. (2008). MENTOR - A Methodology for Enterprise Reference Ontology Development. In: 2008 4th International IEEE Conference on Intelligent Systems.

Sarraipa J., Agostinho C., Panetto H., Jardim-Goncalves R. (2009). Semantic Enrichment of Standard-based Electronic Catalogues. Proceedings of the 13th IFAC 
Symposium on Information Control Problems in Manufacturing, Moscow, Russia, June 3-5. IFAC Papersonline.

Sendall, S., Strohmeier, A. (2001). Requirements Analysis with Use Cases, v1.0. In: SWEED 2001.

SMART-fm (2002). IMS Project No. 01009. A Standards compliant framework to support complete integrated product life-cycle information Management And electronic commerce for the furniture manufacturing (FM) industry, in the advent of the smart enterprises.

SMART-fm (2006). SMART-fm Final Report by EC, UNINOVA and AIDIMA.

Soergel, D. (1997). Multilingual thesauri in cross-language text and speech retrieval. In: AAAI Symposium on CrossLanguage Text and Speech Retrieval, March 24-26, Stanford, California, USA.SMART-fm. (2004). A standards-compliant framework to support complete integrated product life-cycle information management and electronic commerce for the furniture manufacturing ( $\mathrm{fm}$ ) industry, in the advent of the smart enterprises. EC project No. IST-2001-52224

Willerval, B., Boisseau, Y., Serres-Cousiné, H. (Eds) (1989). Le petit Larousse illustré. Librairie Larousse.

Zobel, R., Filos, E. (2006). Technology Management with a Global Perspective: The Case of IMS. In: PICMET'06 Proceedings, 9-13 July 2006, Istanbul, Turkey. 